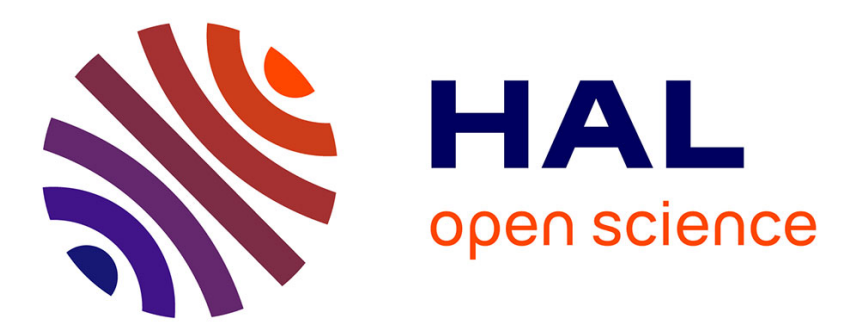

\title{
Impact of droplet composition on the nucleation rate and morphology of vapor-liquid-solid GeSn nanowires
}

Hadi Hijazi, Mohammed Zeghouane, Franck Bassani, Pascal Gentile, Bassem Salem, Vladimir G Dubrovskii

\section{- To cite this version:}

Hadi Hijazi, Mohammed Zeghouane, Franck Bassani, Pascal Gentile, Bassem Salem, et al.. Impact of droplet composition on the nucleation rate and morphology of vapor-liquid-solid GeSn nanowires. Nanotechnology, 2020, 31 (40), pp.405602. 10.1088/1361-6528/ab99f6 . hal-02917562

HAL Id: hal-02917562

https://hal.univ-grenoble-alpes.fr/hal-02917562

Submitted on 18 Oct 2021

HAL is a multi-disciplinary open access archive for the deposit and dissemination of scientific research documents, whether they are published or not. The documents may come from teaching and research institutions in France or abroad, or from public or private research centers.
L'archive ouverte pluridisciplinaire HAL, est destinée au dépôt et à la diffusion de documents scientifiques de niveau recherche, publiés ou non, émanant des établissements d'enseignement et de recherche français ou étrangers, des laboratoires publics ou privés. 
ACCEPTED MANUSCRIPT

\section{Impact of the droplet composition on the nucleation rate and morphology of vapor-liquid-solid GeSn nanowires}

To cite this article before publication: Hadi Hijazi et al 2020 Nanotechnology in press https://doi.org/10.1088/1361-6528/ab99f6

\section{Manuscript version: Accepted Manuscript}

Accepted Manuscript is "the version of the article accepted for publication including all changes made as a result of the peer review process, and which may also include the addition to the article by IOP Publishing of a header, an article ID, a cover sheet and/or an 'Accepted

Manuscript' watermark, but excluding any other editing, typesetting or other changes made by IOP Publishing and/or its licensors"

This Accepted Manuscript is @ 2020 IOP Publishing Ltd.

During the embargo period (the 12 month period from the publication of the Version of Record of this article), the Accepted Manuscript is fully protected by copyright and cannot be reused or reposted elsewhere.

As the Version of Record of this article is going to be / has been published on a subscription basis, this Accepted Manuscript is available for reuse under a CC BY-NC-ND 3.0 licence after the 12 month embargo period.

After the embargo period, everyone is permitted to use copy and redistribute this article for non-commercial purposes only, provided that they adhere to all the terms of the licence https://creativecommons.org/licences/by-nc-nd/3.0

Although reasonable endeavours have been taken to obtain all necessary permissions from third parties to include their copyrighted content within this article, their full citation and copyright line may not be present in this Accepted Manuscript version. Before using any content from this article, please refer to the Version of Record on IOPscience once published for full citation and copyright details, as permissions will likely be required. All third party content is fully copyright protected, unless specifically stated otherwise in the figure caption in the Version of Record.

View the article online for updates and enhancements. 


\title{
Impact of the droplet composition on the nucleation rate and morphology of vapor-liquid-solid GeSn nanowires
}

\author{
Hadi Hijazi ${ }^{1, *}$, Mohammed Zeghouane ${ }^{2}$, Franck Bassani ${ }^{2}$, Pascal Gentile ${ }^{3}$, Bassem Salem ${ }^{2}$, Vladimir G \\ Dubrovskii ${ }^{4}$ \\ ${ }^{1}$ ITMO University, Kronverkskiy pr. 49, 197101 St. Petersburg, Russia \\ ${ }^{2}$ Univ. Grenoble Alpes CNRS, CEA/LETI Minatec, LTM, 38054 Grenoble, France \\ ${ }^{3}$ Univ. Grenoble Alpes, CEA, IRIG-DEPHY, PHELIQS/SINAPS, F-38054 Grenoble, France \\ ${ }^{4}$ St. Petersburg State University, Universitetskaya Emb. 13B, 199034, St. Petersburg, Russia
}

E-mail:* hijazi@itmo.ru

Received xxxxxx

Accepted for publication $\mathrm{xxxxxx}$

Published xxxxxx

\begin{abstract}
It is well-known that chemical potential driving the vapor-liquid-solid growth of semiconductor nanowires is strongly affected by the liquid phase composition. Here, we investigate theoretically how the droplet composition influences the nucleation of Au-catalyzed GeSn nanowires on Ge(111) and $\mathrm{Si}(111)$ substrates. We compare chemical potentials in an Au-Ge-Sn catalyst droplet before and after adding Ga and/or Si atoms. It is found that the presence of these atoms enhances the nucleation rate of nanowires on both substrates. Theoretical results are compared to experimental data on GeSn nanowires grown in hot-wall reduced pressure chemical vapor deposition reactor. It is shown that the intentional addition of $\mathrm{Ga}$ in the de-wetting step improves the uniformity of the nanowire dimensions and yields higher density of nanowires over $\mathrm{Ge}(111)$ substrates. The nanowire growth on $\mathrm{Si}(111)$ substrate occurs only when $\mathrm{Ga}$ and/or $\mathrm{Si}$ are added to $\mathrm{Au}$ droplets. These results show that controlling the composition of the catalyst droplet is crucial for improving the quality of GeSn nanowires.
\end{abstract}

Keywords: Vapor-liquid-solid growth, GeSn nanowires, droplet composition, nucleation rate.

\section{Introduction}

Semiconductor nanowires (NWs) haye attracted much interest as fundamental building blocks for nanoscience and nanotechnology. Particularly elemental and binary group IV-based NWs have shown great promise for different applications.[1-5] Bottom-up NWs are usually grown by the vapor-liquid-solid (VLS) method with a metal droplet which can be made either of one of the growth constituencies in the self-catalyzed approach [6,7] or of a foreign element such as Au [8-10]. Different growth techniques are used to grow NWs, including molecular beam epitaxy [11-13] and chemical vapor deposition (CVD). [14,15] One of the most interesting binary material within group IV-based semiconductor family is $\mathrm{Ge}_{1-\mathrm{x}} \mathrm{Sn}_{\mathrm{x}}$, which opens up a possibility for achieving direct bandgap in group IV semiconductors.[16-20] NWs have been proven efficient for growing GeSn material with a high Sn concentration of $\sim 9 \%$ needed to achieve direct bandgap despite a low equilibrium solubility of $\mathrm{Sn}$ in $\mathrm{Ge}(\sim 1 \%)$ and a large lattice mismatch (14\%).[9,10, 21,22] This may enable monolithic integration of direct bandgap group IV semiconductor with Si electronic platform and pave new ways for fabrication of cheap and highly efficient nanooptoelectronic devices. [23,24]

It is well-known that the composition of a catalyst droplet influences many properties of VLS semiconductor NWs, including their crystal phase, [25,26] doping, [27] growth rate, [28] chemical composition, [29] growth direction [30] and morphology $[31,32]$. In addition to the growth species (atoms to be transferred from vapor to the solid state through liquid), the droplet often contains impurities that may affect the nucleation rate and further growth of NWs. The driving force for NW growth is the chemical potential difference 
$\Delta \mu$ between the liquid and solid phase. This $\Delta \mu$ depends on the growth temperature and atom-fractions of different species dissolved in a catalyst droplet. Interatomic interactions between different species in liquid are described by the corresponding binary and higher order interaction parameters. [33,34] Therefore, each atom present in the droplet must be accounted for when describing nucleation and growth of NWs.

Foreign atoms may be added to the droplet prior to growth in the de-wetting step. Unintentional impurities may originate from the substrate, especially when the sample is heated up to a high temperature. [34-36] For example, the nucleation rate of GaAs NWs on GaAs substrates is enhanced due to the absorption of additional $\mathrm{Ga}$ atoms evaporated from the substrate. [36] When GaAs NWs are grown on $\mathrm{Si}$ substrates, $\mathrm{Si}$ atoms evaporating from the substrate in the de-wetting step may completely suppress nucleation of NWs. [34] Foreign atoms can also be added intentionally by predeposing different metals to form an alloyed rather than pure Au catalyst droplet. [37] It is paramount therefore to have the full appreciation of the influence of the alloy composition on the nucleation, growth and resulting properties of NWs.

Consequently, here we develop a thermodynamic model to quantify how adding $\mathrm{Ga}$ and/or Si atoms to Au droplets influences the VLS growth of GeSn NWs. Our approach is based on the calculation of chemical potential for a mixture of different species present in the droplet, with the solid phase consisting of pure GeSn. We compare the model predictions with experimental data on GeSn NWs grown by Au-catalyzed CVD on $\mathrm{Ge}(111)$ and $\mathrm{Si}(111)$ substrates and show a good quantitative correlation. The model can be further used to study the influence of foreign impurities on the VLS growth of different semiconductor NWs on different substrates. Such calculation enables, first, to avoid pregrowth annealing of samples when the absorption of atoms from the substrate inhibits the NWs growth, and second, to deposit suitable thin films before the dewetting step.

\section{Experimental}

GeSn NWs were grown in hot-wall reduced pressure CVD reactor (Easy Tube 3000 First Nano). Two types of substrates were used, $\mathrm{Ge}(111)$ (system I) and $\mathrm{Si}(111)$ (system II). Prior to growth, all samples were chemically etched in an aqueous hydrofluoric solution to remove native oxides. Then, five different samples were prepared with different catalyst droplets compositions: pure $\mathrm{Au}$ on $\mathrm{Ge}(111)$ substrate (sample S1), Au-Ga on $\mathrm{Ge}(111)$ substrate (sample S2), pure $\mathrm{Au}$ on $\mathrm{Si}(111)$ substrate (sample S3), Au-Si on Si(111) substrate (sample S4), and Au-Ga-Si on Si(111) substrate (sample S5). Au and Au-Ga droplets were obtained by depositing $3 \mathrm{~nm}$ thick $\mathrm{Au}$ and $5 \mathrm{~nm}$ thick $\mathrm{Au}+3 \mathrm{~nm}$ thick Ga thin films, respectively, at room temperature, followed by the annealing step at a temperature of $350{ }^{\circ} \mathrm{C}$ which serves for thermal de-wetting of thin films into droplets. $\mathrm{Si}$ atoms were added to the droplets of samples S4 and S5 by annealing at $550{ }^{\circ} \mathrm{C}$ for 10 minutes before cooling down and initiating the NW growth. This high temperature annealing activated the diffusion of Si from the substrate into the droplets, as in Refs. [34,35]. Germane $\left(\mathrm{GeH}_{4}\right)$ and tin tetrachloride $\left(\mathrm{SnCl}_{4}\right)$ gases were used as $\mathrm{Ge}$ and $\mathrm{Sn}$ precursors, respectively. An additional $\mathrm{HCl}$ flow was maintained at $20 \mathrm{sccm}$ to improve the NWs morphology and suppress the parasitic nucleation on the substrates. Hydrogen was used as a carrier gas and the total pressure was fixed at 4.5 Torr. The morphologies of as-grown GeSn NWs were characterized by scanning electron microscopy (SEM).

\section{Model}

We consider a NW of a given semiconductor material growing in the VLS mode from a supersaturated liquid droplet which contains $n$ species. Initially, the droplet contains no foreign atoms. We will now add $\mathrm{N}_{\varepsilon}$ atoms of one foreign element to this droplet and study the change of the chemical potential difference $\Delta \mu$ between the liquid and solid phase induced by this process. We assume that the solid phase remains pure and hence the incorporation of foreign atoms into the $\mathrm{NW}$ is not accounted for. In this case, the chemical potential change depends only on the state of liquid. The shift $\rho_{\text {I }}$ of $\Delta \mu$ from its initial value $\Delta \mu_{0}$ without any foreign atoms can be written as:

$$
\rho_{\mathrm{I}}=\sum_{\mathrm{X}} \mu_{\varepsilon}^{\mathrm{X}, \mathrm{L}}-\mu_{0}^{\mathrm{X}, \mathrm{L}}
$$

Here, $x$ represents the growth species, while $\mu_{0}^{x, L}$ and $\mu_{\varepsilon}^{\mathrm{X}, \mathrm{L}}$ are their chemical potentials in liquid before and after adding $\mathrm{N}_{\varepsilon}$ foreign atoms to the catalyst droplet, respectively. These chemical potentials are calculated using the regular solution model: [33]

$$
\begin{aligned}
\mu^{\mathrm{X}, \mathrm{L}}= & \mu^{\mathrm{x}, \mathrm{PL}}+\mathrm{k}_{\mathrm{B}} \mathrm{T} \ln \left(\mathrm{c}_{\mathrm{x}}\right)+ \\
& \frac{1}{2} \sum_{\mathrm{i}, \mathrm{j}=1}^{\mathrm{n}+1} \mathrm{c}_{\mathrm{i}} \mathrm{c}_{\mathrm{j}}\left(\omega_{\mathrm{ix}}+\omega_{\mathrm{jx}}-\omega_{\mathrm{ij}}\right),
\end{aligned}
$$

where $\mu^{\mathrm{x}, \mathrm{PL}}$ is the chemical potential of element $\mathrm{x}$ in pure liquid, $\mathrm{k}_{\mathrm{B}}$ is the Boltzmann constant and $\mathrm{T}$ is the absolute temperature. The $\mathrm{c}_{\mathrm{q}}=\mathrm{N}_{\mathrm{q}} / \mathrm{N}_{\text {tot }}$ is the atomic fraction of element $\mathrm{q}$, with $\mathrm{N}_{\mathrm{q}}$ as the number of atoms of 
element $\mathrm{q}$ in the droplet containing the total number of atoms $\mathrm{N}_{\text {tot }}$. These $\mathrm{c}_{\mathrm{q}}$ are obtained simply by noting that adding $\mathrm{N}_{\varepsilon}$ foreign atoms to the droplet increases $\mathrm{N}_{\text {tot }}$, and therefore reduces the initial atomic fractions $c_{\mathrm{q}}^{0}$ of all other species.[34] This gives:

$$
\mathrm{c}_{\mathrm{q}}=\mathrm{c}_{\mathrm{q}}^{0} \cdot\left(1-\mathrm{c}_{\varepsilon}\right) \text {, }
$$

where $c_{\varepsilon}=N_{\varepsilon} / N_{\text {tot }}$ is the atomic fraction of foreign atoms in the droplet.

The concentration-dependent parameters $\omega_{\mathrm{ij}}$ describing binary interactions between elements $i$ and $j$ in the liquid phase are given by: [38]

$$
\omega_{i j}=\frac{1}{N_{A}} \frac{V_{i} V_{j}}{c_{i} V_{i}+c_{j} V_{j}}\left[\left(\delta_{i}-\delta_{j}\right)^{2}-C \frac{\left(\chi_{i}-\chi_{j}\right)^{2}}{\left(V_{i} V_{j}\right)^{1 / 2}}\right] .
$$

Here, $\quad \mathrm{V}_{\mathrm{q}}, \quad \chi_{\mathrm{q}}$ and $\delta_{\mathrm{q}}=\sqrt{\left(\Delta \mathrm{H}_{\mathrm{at}, \mathrm{q}}-\mathrm{RT}\right) / \mathrm{V}_{\mathrm{q}}}$ are respectively the molar volume, the Pauling electronegativity and the Hildebrand solubility parameter of element q, where $\Delta \mathrm{H}_{\mathrm{at}}$ is the enthalpy of atomization and $\mathrm{R}$ is the ideal gas constant. $\mathrm{N}_{\mathrm{A}}$ is the Avogadro number, and $\mathrm{C}$ is a constant which equals $1.256 \times 10^{5}$ if all quantities are in SI units.

After some calculation, the liquid chemical potential of element $\mathrm{x}$ upon adding $\mathrm{N}_{\varepsilon}$ foreign atoms can be rewritten as:

$$
\mu_{\varepsilon}^{\mathrm{X}, \mathrm{L}}=2 \mathrm{k}_{\mathrm{B}} \mathrm{T} \ln \left(1-\mathrm{c}_{\varepsilon}\right)+\xi_{\mathrm{x}} \mathrm{c}_{\varepsilon}+\lambda_{\mathrm{x}} \mathrm{c}_{\varepsilon}^{2}+\gamma_{\mathrm{x}},
$$

with

$$
\begin{aligned}
& \xi_{\mathrm{x}}=- \sum_{\mathrm{i}, \mathrm{j}=1}^{\mathrm{n}} c_{\mathrm{i}}^{0} c_{\mathrm{j}}^{0}\left(\omega_{\mathrm{i}, \mathrm{x}}+\omega_{\mathrm{j}, \mathrm{x}}-\omega_{\mathrm{i}, \mathrm{j}}\right)+ \\
& \sum_{\mathrm{i}=1}^{\mathrm{n}} \mathrm{c}_{\mathrm{i}}^{0}\left(\omega_{\mathrm{i}, \mathrm{x}}+\omega_{\varepsilon, \mathrm{x}}-\omega_{\mathrm{i}, \varepsilon}\right), \\
& \lambda_{\mathrm{x}}=\frac{1}{2} \sum_{\mathrm{i}, \mathrm{j}=1}^{\mathrm{n}} c_{\mathrm{i}}^{0} c_{\mathrm{j}}^{0}\left(\omega_{\mathrm{i}, \mathrm{x}}+\omega_{\mathrm{j}, \mathrm{x}}-\omega_{\mathrm{i}, \mathrm{j}}\right)- \\
& \\
& \sum_{\mathrm{i}=1}^{\mathrm{n}} \mathrm{c}_{\mathrm{i}}^{0}\left(\omega_{\mathrm{i}, \mathrm{x}}+\omega_{\varepsilon, \mathrm{x}}-\omega_{\mathrm{i}, \varepsilon}\right)+\omega_{\varepsilon, \mathrm{x}}, \\
& \gamma_{\mathrm{x}}=\frac{1}{2} \sum_{\mathrm{i}, \mathrm{j}=1}^{\mathrm{n}} c_{\mathrm{i}}^{0} c_{\mathrm{j}}^{0}\left(\omega_{\mathrm{i}, \mathrm{x}}+\omega_{\mathrm{j}, \mathrm{x}}-\omega_{\mathrm{i}, \mathrm{j}}\right) .
\end{aligned}
$$

Using these expressions, Eq. (1) can be rewritten as:

$$
\rho_{\mathrm{I}}=2 \mathrm{k}_{\mathrm{B}} \mathrm{T} \ln \left(1-\mathrm{c}_{\varepsilon}\right)+\Omega \mathrm{c}_{\varepsilon}+\Lambda \mathrm{c}_{\varepsilon}^{2},
$$

where $\Lambda=\sum_{\mathrm{x}} \lambda_{\mathrm{x}}$ and $\Omega=\sum_{\mathrm{x}} \xi_{\mathrm{x}}$. This generalizes the result of Ref. [34] to the case of arbitrary composition of a droplet containing $\mathrm{n}$ species and 1 type of foreign atoms.
The same calculation can be done to describe system II in which two foreign elements ( $\mathrm{Ga}$ and $\mathrm{Si}$ ) with the numbers of atoms $\mathrm{N}_{\varepsilon 1}$ and $\mathrm{N}_{\varepsilon 2}$ are added to the liquid droplet. The corresponding atomic fractions of the two elements in liquid equal $\mathrm{c}_{\varepsilon 1}$ and $\mathrm{c}_{\varepsilon 2}$, respectively. In this case, the atomic fractions of the other species in liquid should be modified to:

$$
\mathrm{c}_{\mathrm{q}}=\mathrm{c}_{\mathrm{q}}^{0} \cdot\left(1-\mathrm{c}_{\varepsilon 1}-\mathrm{c}_{\varepsilon 2}\right) .
$$

Following the same method, the change of chemical potential is obtained in the form:

$$
\begin{aligned}
\rho_{\mathrm{II}}= & 2 \mathrm{k}_{\mathrm{B}} \mathrm{T} \ln \left(1-\mathrm{c}_{\varepsilon 1}-\mathrm{c}_{\varepsilon 2}\right)+\Lambda_{1} \mathrm{c}_{\varepsilon 1}^{2}+ \\
& \Lambda_{2} \mathrm{c}_{\varepsilon 2}^{2}+\sigma \mathrm{c}_{\varepsilon 1} \mathrm{c}_{\varepsilon 2}+\Omega_{1} \mathrm{c}_{\varepsilon 1}+\Omega_{2} \mathrm{c}_{\varepsilon 2},
\end{aligned}
$$

with

$$
\begin{gathered}
\Lambda_{\mathrm{q}}=\sum_{\mathrm{x}}\left\{\frac{1}{2} \sum_{\mathrm{i}, \mathrm{j}=1}^{\mathrm{n}} \mathrm{c}_{\mathrm{i}}^{0} c_{\mathrm{j}}^{0}\left(\omega_{\mathrm{i}, \mathrm{x}}+\omega_{\mathrm{j}, \mathrm{x}}-\omega_{\mathrm{i}, \mathrm{j}}\right)-\right. \\
\left.\sum_{\mathrm{i}=1}^{\mathrm{n}} c_{\mathrm{i}}^{0}\left(\omega_{\mathrm{i}, \mathrm{x}}+\omega_{\varepsilon q, \mathrm{x}}-\omega_{\mathrm{i}, \varepsilon q}\right)+\omega_{\varepsilon q, \mathrm{x}}\right\}, \\
\sigma=\sum_{\mathrm{i}, \mathrm{j}=1}^{\mathrm{n}} c_{\mathrm{i}}^{0} c_{\mathrm{j}}^{0}\left(\omega_{\mathrm{i}, \mathrm{x}}+\omega_{\mathrm{j}, \mathrm{x}}-\omega_{\mathrm{i}, \mathrm{j}}\right)- \\
\sum_{\mathrm{i}=1}^{\mathrm{n}} c_{\mathrm{i}}^{0}\left(2 \omega_{\mathrm{i}, \mathrm{x}}+\omega_{\varepsilon 1, \mathrm{x}}+\omega_{\varepsilon 2, \mathrm{x}}-\right. \\
\left.\omega_{\mathrm{i}, \varepsilon 1}-\omega_{\mathrm{i}, \varepsilon 2}\right)+\left(\omega_{\varepsilon 1, \mathrm{x}}+\omega_{\varepsilon 2, \mathrm{x}}-\omega_{\varepsilon 1, \varepsilon 2}\right), \\
\Omega_{\mathrm{q}}=\sum_{\mathrm{x}}\left\{-\sum_{\mathrm{i}, \mathrm{j}=1}^{\mathrm{n}} c_{\mathrm{i}}^{0} c_{\mathrm{j}}^{0}\left(\omega_{\mathrm{i}, \mathrm{x}}+\omega_{\mathrm{j}, \mathrm{x}}-\omega_{\mathrm{i}, \mathrm{j}}\right)+\right. \\
\left.\sum_{\mathrm{i}=1}^{\mathrm{n}} c_{\mathrm{i}}^{0}\left(\omega_{\mathrm{i}, \mathrm{x}}+\omega_{\varepsilon q, \mathrm{x}}-\omega_{\mathrm{i}, \varepsilon q}\right)\right\} .
\end{gathered}
$$

\begin{tabular}{|c|c|c|c|}
\hline Element & $\begin{array}{c}\mathrm{V} \\
\left(\mathrm{cm}^{3} \cdot \mathrm{mol}^{-1}\right)\end{array}$ & $\begin{array}{c}\Delta H_{\text {at }} \\
\left(10^{24} \text { eV. } \text { mol }^{-1}\right)\end{array}$ & $\chi$ \\
\hline $\mathbf{A u}$ & 11.3790 & 2.285 & 2.54 \\
\hline Ga & 11.8095 & 1.729 & 1.81 \\
\hline Ge & 12.9696 & 2.353 & 1.90 \\
\hline Sn & 16.2394 & 1.885 & 1.96 \\
\hline $\mathbf{S i}$ & 11.2724 & 2.846 & 2.01 \\
\hline
\end{tabular}

According to Ref. [34], the NW nucleation rate rapidly increases with increasing the chemical potential of the liquid phase. Therefore, positive chemical potential difference $\rho$ eases and negative $\rho$ suppresses nucleation of VLS NWs by adding one or two foreign elements to the catalyst droplet.

\section{Results and discussion}

We will now apply the model to study the growth systems presented above. Parameters of different elements used in calculations are summarized in table 1.

Table 1: Parameters used in calculations of the binary interaction parameters $\omega_{\mathrm{ij}}$. 


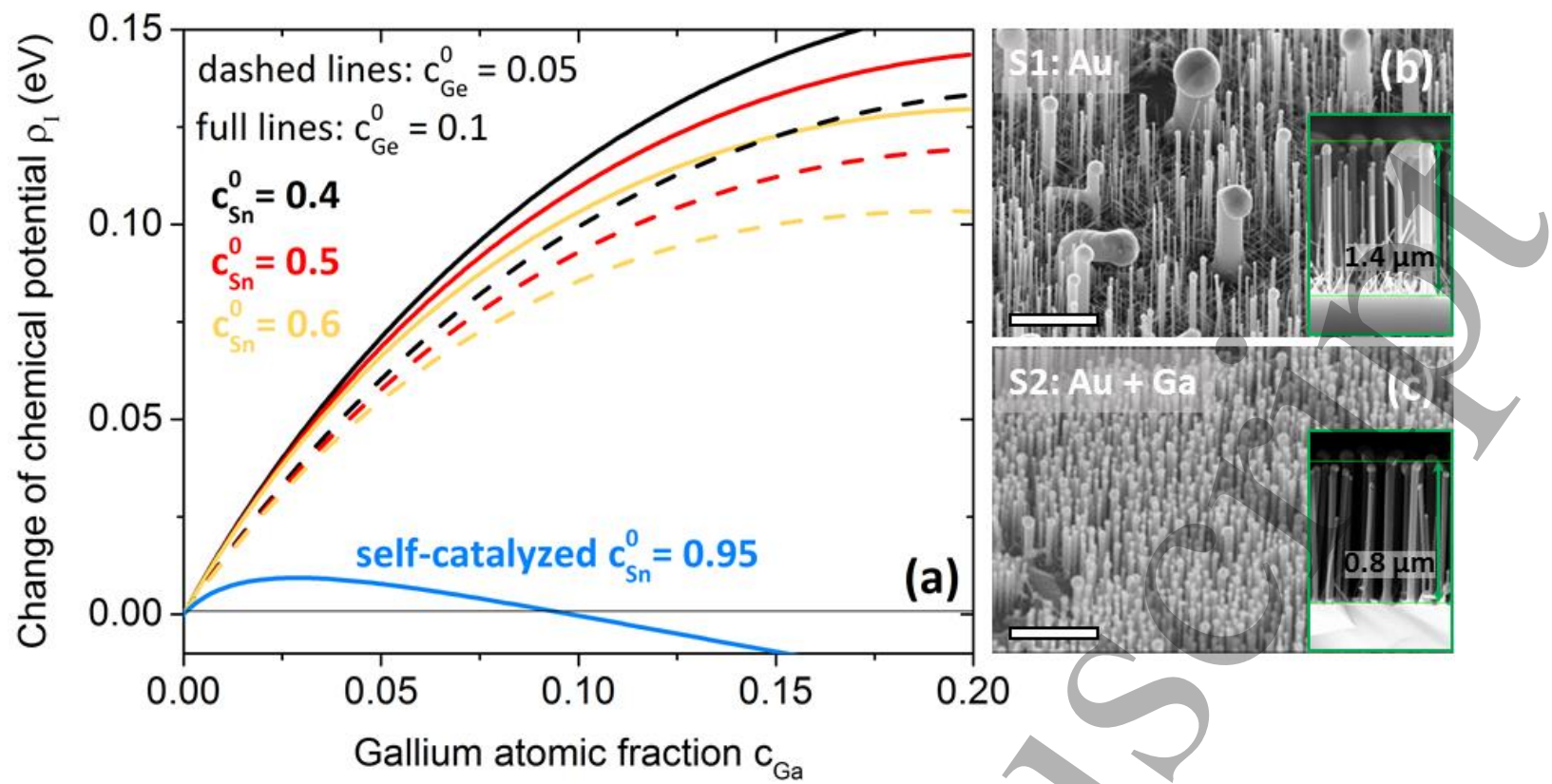

Figure 1: (a) Evolution of the chemical potential change $\rho_{\mathrm{I}}$ versus atomic fraction of Ga added to the droplets of different composition. The growth temperature is $350{ }^{\circ} \mathrm{C}$. Blue full line corresponds to the Sn-catalyzed vapor-liquid-solid process without any $\mathrm{Au}$. The other curves correspond to the Au-catalyzed vapor-liquid-solid process with different initial atomic fractions of $\mathrm{Sn}_{\mathrm{Sn}}^{0}$. Full and dashed lines represent initial atomic fraction of $\mathrm{Ge}_{\mathrm{Ge}}^{0}=0.05$ and 0.1 , respectively. Panels (b) and (c) show scanning electron microscopy images of GeSn NWs grown on $\mathrm{Ge}(111)$ substrates with pure $\mathrm{Au}(\mathrm{S} 1)$ and $\mathrm{Au}-\mathrm{Ga}(\mathrm{S} 2)$ catalyst droplets, respectively. The inserts show cross-section views with the measured NW lengths. Scale bars correspond to $1 \mu \mathrm{m}$.

We first consider GeSn NWs grown on Ge(111) temperature. [41] We can see that lower $\mathrm{Sn}$ substrate (system I). The initial liquid phase is a ternary concentrations in the catalyst droplet enhance the Au-Ge-Sn alloy, to which we add Ga atoms $(\varepsilon=\mathrm{Ga})$. chemical potential difference. More quantitatively, an Adding foreign elements, such as Ga in this case, to the increase of the chemical potential difference up to $\sim 150$ droplet can increase the degree of supersaturation and provide an effective method to enhance the $\mathrm{NW}$ nucleation rate. In addition, binary phase diagrams of $\mathrm{Sn}$ or $\mathrm{Ge}$ with $\mathrm{Ga}$ indicate the existence of low eutectic temperatures (from 20 to $29^{\circ} \mathrm{C}$ ), which may allow for lowering the growth temperatures of GeSn NWs. Figure 1 (a) shows the evolution of $\rho_{\mathrm{I}}$ with $\mathrm{c}_{\mathrm{Ga}}$. The curves are obtained from Eq. (6) for different $c_{G e}^{0}$ and $c_{S n}^{0}$, in Aucatalyzed VLS growth processes at a fixed growth temperature $\mathrm{T}$ of $350{ }^{\circ} \mathrm{C}$. These $\mathrm{c}_{\mathrm{Ge}}^{0}$ and $\mathrm{c}_{\mathrm{Sn}}^{0}$ were estimated from the Au-Sn-Ge ternary phase diagram. [39] Positive values of $\rho_{\mathrm{I}}$ obtained in a wide range of concentrations reveal that the presence of $\mathrm{Ga}$ always enhances the nucleation and growth rates of $\mathrm{Au}$ catalyzed GeSn NWs. For self-catalyzed process where $\mathrm{c}_{\mathrm{Sn}}^{0}$ is fixed at $0.95,[40] \rho_{\mathrm{I}}$ also increases at low $\mathrm{c}_{\mathrm{Ga}}$ but starts to decrease below zero when $\mathrm{c}_{\mathrm{Ga}}$ is greater than 0.1 . This value is however hardly reachable because the solubility of Ga in Sn droplet is almost zero at the growth $\mathrm{meV}$ can occur in Au-rich droplets. This will lead to rising the NW nucleation rate by several orders of magnitude, because the nucleation probability depends exponentially on $\rho$. [34,42]

Let us now compare these results with experimental observations. Figures 1 (b) and (c) show tilted-view SEM images of samples S1 and S2, respectively. In both cases, GeSn NWs grow preferentially along the [111] direction perpendicular to the substrate surface. The NW diameter is relatively uniform along its entire length. This can be attributed to the passivation of the NW sidewalls by chlorine atoms as previously discussed in Ref. [43]. However, random nucleation of Au-catalyzed NWs on the substrate surface in sample S1 is revealed by the broad distribution of diameters within the NW ensemble. The largest NWs are surrounded by the depleted zones where no other NWs or droplets are observed. On the other hand, NWs catalyzed by Au-Ga droplets in sample S2 show a much narrower distribution of diameters, larger surface density and more uniform

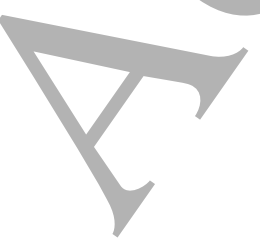


2

3

4

5

6

7

8

9

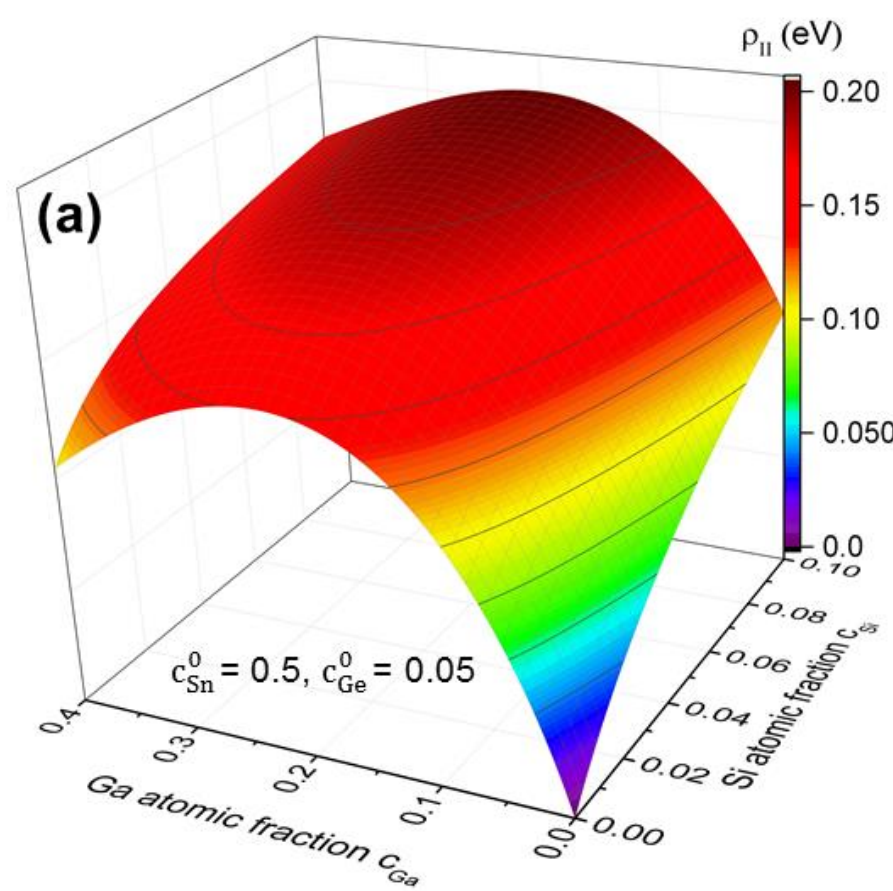

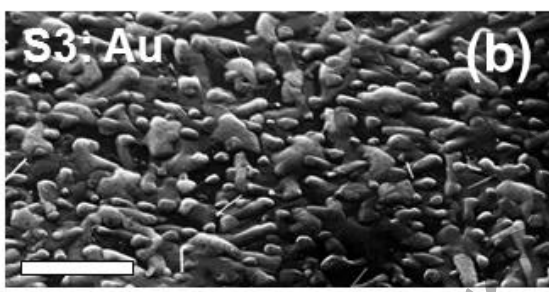
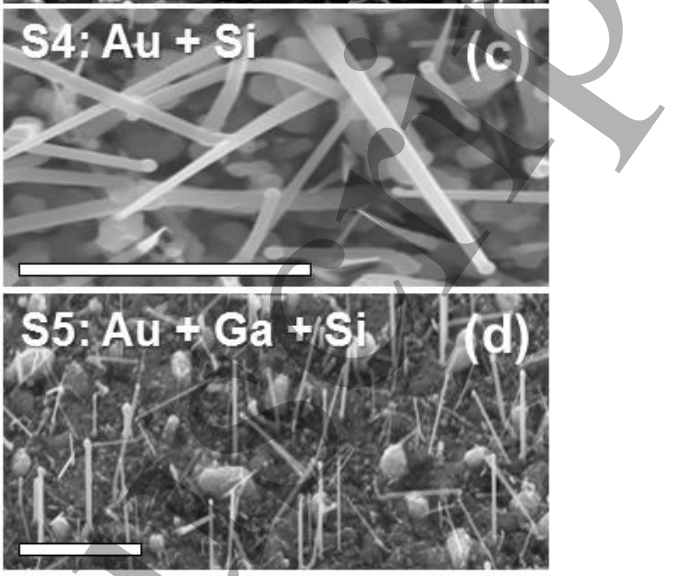

Figure 2: (a) Three-dimensional map showing the chemical potential change $\rho_{\text {II }}$ versus the atomic fractions of $\mathrm{Ga}$ and $\mathrm{Si}$ in the catalyst droplet. The initial atomic fractions $\mathrm{c}_{\mathrm{Ge}}^{0}$ and $\mathrm{c}_{\mathrm{Sn}}^{0}$ are fixed at 0.05 and 0.5 , respectively. The growth temperature is $350^{\circ} \mathrm{C}$. (b-d) Scanning electron microscopy images of GeSn NWs grown on $\mathrm{Si}(111)$ substrates under the following conditions: (b) deposition of Au without annealing, (c) deposition of $\mathrm{Au}$ followed by annealing at $550{ }^{\circ} \mathrm{C}$ for 10 minutes, (d) deposition of Au and Ga followed by annealing at $550{ }^{\circ} \mathrm{C}$ for 10 minutes. Scale bars correspond to $1 \mu \mathrm{m}$.

spatial distribution over the substrate surface, revealing results in the depletion zones observed around the largest their synchronized nucleation. Note that both samples NWs in figure 1 (b).

were grown under the same conditions: a growth

temperature of $350{ }^{\circ} \mathrm{C}$, a growth time of 60 minutes and $\mathrm{a} \mathrm{GeH}_{4} / \mathrm{SnCl}_{4}$ flux ratio of $10^{-3}$. The growth temperature employed corresponds to the optimal conditions for the Au-catalyzed VLS growth of GeSn NWs determined in our previous work. [21] As shown in the inserts of figures 1 (b) and (c), the NW growth rate is reduced by a factor $\sim 1.75$ in the presence of $\mathrm{Ga}$ in the droplet.

Based on these data, we propose the following explanations for the observed difference in the morphology of GeSn NWs obtained with pure Au or AuGa droplets.

(1) Due to a lower nucleation probability of NWs emerging from pure Au droplets following from figure 1 (a), the incubation time required to start the NWs from the substrate is longer in sample S1. This allows larger droplets to collect the surrounding smaller ones by the Ostwald ripening process and increase their sizes before initiating the NW growth, similarly to Ref. [35]. This
(2) For NWs catalyzed by Au-Ga droplets, the initial nucleation is easier according to figure 1 (a). This effect leads to more synchronized nucleation of NWs in sample S2 and explains their larger surface density, smaller diameters and higher degree of spatial uniformity seen in figure 1 (c). This trend was systematically observed for different $\mathrm{Au}$ and $\mathrm{Ga}$ films thicknesses tested (not shown).

(3) Due to a difficult nucleation of NWs emerging from pure Au droplets, these droplets remain in contact with Ge substrate for a longer time. Consequently, NWs of sample $\mathrm{S} 1$ receive more $\mathrm{Ge}$ atoms from the substrate compared to sample S2. Higher Ge concentration in the

droplets after nucleation enhances the growth rate of these NWs, [44] as is seen from figure 1 (a). This explains why the NWs in sample S1 are longer than in sample S2.

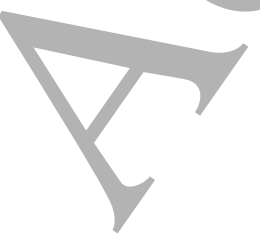


It is important to note that the variation in chemical potential driving the NW nucleation is sensitive to the vapor phase composition. For example, it was experimentally demonstrated that increasing the $\mathrm{P}_{\mathrm{SnCl}_{4}} / \mathrm{P}_{\mathrm{GeH}_{4}}$ partial pressure ratio results in a reduced growth of Au-catalyzed GeSn NW on Ge(111) substrates. [21] In other words, the NW nucleation and growth rates are decreased by depositing more Sn and less $\mathrm{Ge}$ onto the $\mathrm{Au}$ droplet. This property also clearly follows from the graphs in figure 1 (a).

We now consider system II which corresponds to GeSn NWs grown on $\mathrm{Si}(111)$ substrates, where $\mathrm{Si}$ can be transferred to the droplets in the high temperature annealing step. The initial droplet is a ternary Au-Ge-Sn alloy, to which we add $\mathrm{Ga}$ and $\mathrm{Si}\left(\varepsilon_{1}=\mathrm{Ga}, \varepsilon_{2}=\mathrm{Si}\right)$. Figure 2 (a) shows three-dimensional map of the chemical potential difference $\rho_{\mathrm{II}}$ versus $\mathrm{c}_{\mathrm{Ga}}$ and $\mathrm{c}_{\mathrm{Si}}$, obtained from Eq. 8 with $\mathrm{c}_{\mathrm{Ge}}^{0}$ and $\mathrm{c}_{S n}^{0}$ fixed at 0.05 and 0.5 , respectively. The growth temperature is the same as in system I. Considering first the dependence of $\rho_{\text {II }}$ on $\mathrm{c}_{\mathrm{Ga}}$ at a fixed $\mathrm{c}_{\mathrm{Si}}$, we can see that the presence of $\mathrm{Ga}$ is always favorable for the NW nucleation. This is confirmed experimentally in figures 2 (b) and (d), where the NWs emerge only in the presence of Ga. The nucleation rate and hence the incubation time required to start the NWs from the substrate is now different for different concentrations of Si in the droplet. Considering the evolution of $\rho_{\mathrm{II}}$ with $\mathrm{c}_{\mathrm{Si}}$ at a fixed $\mathrm{c}_{\mathrm{Ga}}$, figure 2 (a) shows that $\rho_{\text {II }}$ monotonically increases with $c_{\text {Si }}$ even at $\mathrm{c}_{\mathrm{Ga}}=0$. This explains the presence of GeSn NWs in the annealed sample S5 [figure 2 (c)] and their absence in sample S3 where the droplets consist of pure Au [figure 2 (b)].

Overall, these results show that GeSn NWs cannot be grown on $\mathrm{Si}(111)$ substrates with pure $\mathrm{Au}$ catalyst. Adding only Si atoms in the high temperature annealing step, as in sample S4, allows the VLS growth of NWs with random position, size and orientation. The NW morphology is largely improved by adding Ga to the Au$\mathrm{Si}$ droplets. However, this growth is much less regular than on $\mathrm{Ge}(111)$ substrates with Au-Ga droplets and needs to be further optimized with respect to other conditions such as temperature, total pressure and composition of the vapor phase.

The Sn concentration in our GeSn NWs grown on both $\mathrm{Ge}(111)$ and $\mathrm{Si}(111)$ substrates, estimated by energy dispersive $\mathrm{X}$-ray spectroscopy, is relatively low, in the range from 1 to $2 \%$, which is only slightly beyond the equilibrium solubility. Previous study has shown that a lower growth temperature is required to achieve Snrich GeSn NWs, with up to $10 \%$ total concentration of of Sn and a limited Sn segregation. [45] Another work revealed an important role of the axial NW growth rate in the non-equilibrium incorporation of $\mathrm{Sn}$ into Ge.[46] Even more delicate dependence of the Sn incorporation may arise due to variable compositions in Au-Ge-Sn-Ga or Au-Ge-Sn-Ga-Si alloy droplets. This study is beyond the scope of this work and will be presented elsewhere. However, our model and data reveal in a consistent manner the impact of the liquid phase composition on the nucleation rate of GeSn NWs influencing their size homogeneity, surface density and morphology on different substrates. The model is not specific for GeSn material and should work in a wide range of materialsubstrate combinations for controlling the properties of different semiconductor NWs by tuning the catalyst composition.

\section{Conclusions}

A model has been developed which allows one to quantify how chemical potential in a catalyst droplet is modified by adding one or two types of foreign elements before the VLS growth of NWs. Au-catalyzed growth of GeSn NWs on Ge(111) and Si(111) substrates from AuGe-Sn droplets with added $\mathrm{Ga}$ and/or Si atoms have been analyzed. For $\mathrm{Ge}(111)$ substrates, it has been shown that nucleation of GeSn NWs is easier when Ga atoms are added to Au catalysts in the de-wetting step. This leads to a higher surface density and enhanced size uniformity within the NW ensembles. For Si(111) substrates, the VLS growth of GeSn NWs can only be achieved with adding $\mathrm{Si}$ or both $\mathrm{Si}$ and $\mathrm{Ga}$ atoms to $\mathrm{Au}$ droplets. Adding $\mathrm{Ga}$ improves the homogeneity of the NW morphology which, however, remains less regular than on $\mathrm{Ge}(111)$ substrates. Overall, these results can be used for optimizing nucleation and growth of semiconductor NWs on different substrates by adding suitable foreign atoms to the catalyst droplets.

Acknowledgments: H.H. and V.G.D. are grateful to the Russian Science Foundation for financial support under the Grant 19-72-30004.

Conflicts of interest: The authors declare no conflict of interest.

\section{References:}

[1] Le S T, Jannaty P, Luo X, Zaslavsky A, Perea D E, Dayeh S A and Picraux S T 2012 Axial SiGe heteronanowire tunneling field-effect transistors Nano Lett. 12 5850-5855 
[2] Wu Y, Fan R and Yang P 2002 Block-by-block growth of single-crystalline $\mathrm{Si} / \mathrm{SiGe}$ superlattice nanowires Nano Lett. 283

[3] Zaima S, Nakatsuka O, Taoka N, Kurosawa M, Takeuchi W and Sakashita M 2015 Growth and applications of GeSn-related group-IV semiconductor materials Sci. Technol. Adv. Mater. 16043502

[4] Wen C Y, Reuter M C, Bruley J, Tersoff S, Kodambaka S, Stach E A and Ross F M 2009 Formation of compositionally abrupt axial heterojunctions in silicon-germanium nanowires Science $\mathbf{3 2 6} 1247$

[5] Rosaz G, Salem B, Pauc N, Potié A, Gentile P and Baron T 2011 Vertically integrated silicon-germanium nanowire field-effect transistor Appl. Phys. Lett. 99 193107

[6] Yu K, Zhang D L, Cong H, Zhang H, Zhao Y, Cheng B W and Li C B 2016 Defect-free GeSn alloy strips on $\mathrm{Si}$ by $\mathrm{Sn}$ self-catalyzed MBE method IEEE $13^{\text {th }}$ International Conference on Group IV Photonics (GFP)

[7] Sun Y L, Matsumura R, Jevasuwan W and Fukuta N $2019 \mathrm{Au}-\mathrm{Sn}$ catalysed growth of $\mathrm{Ge}_{1-\mathrm{x}} \mathrm{Sn}_{\mathrm{x}}$ nanowires: growth direction, crystallinity and $\mathrm{Sn}$ incorporation Nano Lett. 19 6270-6277

[8] Azrak E, Chen W, Moldovan S, Duguay S, Pareige $\mathrm{P}$ and Cabarrocas P R i 2020 Growth of in-plane $\mathrm{Ge}_{1-\mathrm{x}} \mathrm{Sn}_{\mathrm{x}}$ nanowires with 22 at. \% Sn using a solidliquid-solid mechanism J. Phys. Chem. C 124 12201226

[9] Meng A C, Colleen F S, Michael B R, James M P, Ann M F, James H S and Paul M C 2016 Core-shell germanium/germanium-tin nanowires exhibiting roomtemperature direct- and indirect-gap photoluminescence Nano Lett. 16 7521-7529

[10] Biswas S, Jessica D, Dzianis S, Quentin R, Dipanwita M, Moneesh U, Achintya S, Tomsz O, Michael M A and Justin H D 2016 Non-equilibrium induction of tin in germanium: towards direct bandgap $\mathrm{Ge}_{1-\mathrm{x}} \mathrm{Sn}_{\mathrm{x}}$ nanowires Nature Communications 711405

[11] Han D, Ye H, Song H, Zhu Z, Yang Y, Yu Z, Liu Y, Wang S and Di Z 2019 Analysis of Raman scattering from inclined $\mathrm{GeSn} / \mathrm{Ge}$ dual-nanowire heterostructure on Ge(111) substrate Appl. Surf. Sci. 463 581-586
[12] Zhu Z Y S, Song Y X, Han Y, Li Y Y Zhang Z P, Zhang L Y and Wang S M 2017 GeS,/Ge dual-nanowire heterostructure IEEE Photonics Society Summer Topical Meeting Series (SUM)

[13] Zhu Z, Song Y, Zhang Z, Sun H, Han Y, Li Y, Zhang L, Cue Z, Di Z and Wang S 2017 Vapor-solidsolid grown $\mathrm{Ge}$ nanowires at integrated circuit compatible temperature by molecular beam epitaxy $J$. Appl. Phys. 122094304

[14] Periwal P, Sibirev N V, Patriarche G, Salem B, Bassani F, Dubrovskii V G and Baron T 2014 composition-dependent interfacial abruptness in $\mathrm{Au}$ catalyzed $\quad \mathrm{Si}_{1-\mathrm{x}} \mathrm{Ge}_{\mathrm{x}} / \mathrm{Si} / \mathrm{Si}_{1-\mathrm{x}} \mathrm{Ge}_{\mathrm{x}}$ nanowire heterostrucures Nano Lett. 14 5140-7

[15] Albani M, Assali S, Verheijen M A, Koelling S, Bergamashini R, Pezzoli F, Bakkers E P A M and Miglio L 2018 Critical strain for Sn incorporation in spontaneously graded Ge/GeSn core/shell nanowires Nanoscale 10 7250-7356

[16] Kouvetakis J, Memendez J and Chizmeshya A V G 2006 Tin-based group IV semiconductors: new platforms for opto- and microelectronics on silicon Annu Rev. Mater. Res. 36497

[17] Soref R 2010 Silicon photonics: a review of recent literature Silicon 2 1-6

[18] Zhang P, Crespi V H, Chang E, Louie S G and Cohen M L 2001 Computational design of directbandgap semiconductors that lattice-match silicon Nature 409 69-71

[19] Wirths S, Geiger R, von den Driesch N, Mussler G, Stoica T, Mantl S, Ikonic Z, Luysberg M, Chiussi S, Hartmann J M, Sigg H, Faist J, Buca D, Grützmacher D 2015 Lasing in direct-bandgap GeSn alloy grown on $\mathrm{Si}$ Nature Photonics 9 88-92

[20] Stange D., Wirths S., von den Driesch N, Mussler G, Stoica T, Ikonic Z, Hartmann J M, Mantl S, Grützmacher D and Buca D 2015 Optical transitions in direct-bandgap $\mathrm{Ge}_{1-\mathrm{x}} \mathrm{Sn}_{\mathrm{x}}$ alloys ACS Photonics 21539

[21] Haffner T, Zeghouane M, Bassani F, Gentile P, Gassenq A, Chouchane F, Pauc N, Martinez E, Robin E, David S, Baron T and Salem B 2017 Growth of $\mathrm{Ge}_{1-\mathrm{x}} \mathrm{Sn}_{\mathrm{x}}$ nanowires by chemical vapour deposition via 
vapour-liquid-solid mechanism using $\mathrm{GeH}_{4}$ and $\mathrm{SnCl}_{4}$ Phys. Stat. Sol. A 1700743

[22] Assali S, Dijkstra A, Li A, Koelling S, Verheijen M A, Gagliano L, von den Driesch N, Buca D, Koenraad P M, Haverkort J E M and Bakkers E P A M 2017 Growth and optical properties of direct band gap $\mathrm{Ge} / \mathrm{Ge}_{0.87} \mathrm{Sn}_{0.13}$ core/shell nanowire arrays Nano Lett. 17 1538-1544

[23] von den Driesch N Stange D, Wirths S, Mussler G, Holländer B, Ikonic Z, Hartmann J M, Stoioca T, Mantl S, Grützmacher D and Buca D 2015 Direct bandgap group IV epitaxy on $\mathrm{Si}$ for laser applications Chem. Mater. 274693

[24] Sau J D and Cohen M L 2007 Possibility of increased mobility in Ge-Sn alloy system Phys. Rev. B $\mathbf{7 5} 045208$

[25] Glas F, Harmand J C and Patriarche G 2007 Why does wurtzite form in nanowires of III-V zinc blende semiconductors? Phys. Rev. L. 99146101

[26] Gil E, Dubrovskii V G, Avit G, André Y, Leroux C, Lekhal K, Grecenkov J, Trassoudaine A, Castelluci D, Monier G, Ramdani M R, Robert-Goumet C, Bideux L, Harmand J C and Glas F 2014 Record pure zincblende phase in GaAs nanowires down to $5 \mathrm{~nm}$ in radius Nano Lett. 14 3938-3944

[27] Hijazi H, Monier G, Gil E, Trassoudaine A, Bougerol C, Leroux C, Castellucci D, Robert-Goumet C, Hoggan P E, André Y, Goktas N I, LaPierre R R and Dubrovskii V G 2019 Si doping vapor-liquid-solid GaAs nanowires : n-type or p-type ? Nano Lett. 19 4498-4504

[28] Dubrovskii V G 2014 Influence of the group V element on the chemical potential and crystal structure of Au-catalyzed III-V nanowires Appl. Phys. Lett 104 053110

[29] Leshchenko E D, Ghasemi M, Dubrovskii V G and Johansson J 2018 Nucleation-limited composition of ternary III-V nanowires forming from quaternary gold based liquid alloys CrystEng Comm 201649

[30] Panciera F, Baraissov Z, Patriarche G, Dubrovskii V G, Glas F, Travers L, Mirsaidov U and Harmand J C 2020 Phase selection in self-catalyzed GaAs nanowires Nano Lett. 20 1669-1675
[31] Pan D, Wang J-Y, Zhang W, Zhu L, Su X, Fan F, Fu Y, Huang S, Wei D, Zhang L, Sui M, Yartsev A, Xu $\mathrm{H}$ and Zhao J 2019 Dimension engeneering of hoghquality InAs nanostructures on a wafer scale Nano Lett. 19 1632-1642

[32] Jia G and Du J 2018 Foreign metal ions to control the morphology of solution-liquid-solid reaction Cryst. Growth Des. 18 7489-7495

[33] Glas F 2010 Chemical potentials for/Au-assisted vapour-liquid-solid growth of III-V nanowires J. Appl. Phys. 108073506

[34] Hijazi H, Dubrovskii V G, Monier G, Gil E, Leroux C, Avit G, Trassoudaine A, Bougerol C, Castelluci D, Robert-Goumet C and André Y 2018 Influence of Si on the nucleation rate of GaAs nanowires on Si substrates J. Phys. Chem. C 122 19230-19235

[35] Hijazi H, Leroy F, Monier G, Grégoire G, Gil E, Trassoudaine A, Dubrovskii V G, Castelluci D, Goktas N I, LaPierre R R, André Y and Robert-Goumet C 2020 Dynamics of $\mathrm{Au}$ droplet formation on $\mathrm{SiO}_{2} / \mathrm{Si}(111)$ surface J. Phys. Chem. C. accepted

[36] André Y, Lekhal K, Hoggan P E, Avit G, Cadiz F, Rowe A, Paget D, Petit E, Leroux C, Trassoudaine A, Ramdani M R, Monier G, Colas D, Ajib R, Castelluci D and Gil E 2014 Vapor liquid solid-hydride vapour phase epitaxy (VLS-HVPE) growth of ultra-long defect-free GaAs nanowires: $\mathrm{Ab}$ initio simulations supporting center nucleation J. Chem. Phys. 140194706

[37] Hijazi H 2019 HVPE-Grown GaAs Nanowires : Growth Modeling, Passivation and Transport Properties PhD Thesis Université Cermont Auvergne, France

[38] Stringfellow G B 1972 calculation of ternary phase diagrams of III-V systems J. Phys Chem. Solids 33665

[39] Wang J, Leinenbach C and Roth M 2009 Thermodynamic modelling of the Au-Ge-Sn ternary system Journal of Alloys and Compounds 481 830-836

[40] Olesinski R W and Abbaschian G J 1984 The GeSn (germanium-tin) system Bulletin of Alloy Phase Diagrams 5 265-271

[41] Anderson T J and Ansara I 1992 The Ga-Sn (gallium-tin) system JPE 13 181-189 
[42] Dubrovskii V G and Grecenkov J 2015 Zeldovich nucleation rate, self-consistency renormalization, and crystal phase of Au-catalyzed GaAs nanowires Cryst. Growth Des. 15 340-347

[43] Guilloy K, Pauc N, Gentile P, Robin E and Clavo V 2016 Uniform phosphorus doping of untampered germanium nanowires Nanotechnology 27485701

[44] Hajjar S, Garreau G, Josien L, Bubendorff J L, Berling D, Mehdaoui A, Pirri C, Maroutian T, Renard C, Bouchier D, Petit M, Spiesser A, Dau M T, Michez L, Le Thanh V, Mentes T O, Nino M A and Locatelli A 2011 Morphology and composition of Au catalysts on Ge(111) obtained b thermal dewetting Phys. Rev. B 84 125325

[45] Dou W, Benamara M, Mosleh A, Margetis J, Grant P, Zhou Y, Al-Kabi S, Du W, Tolle J, Li B, Mortazavi M and Yu S Q 2018 Investigation of GeSn strain relaxation and spontaneous composition gradient for low-defect and high-Sn alloy growth Sci. Rep. 85640

[46] Grzybowsk G, Beeler R T, Jiang L, Smith D J, Kouvetakis J and Menéndez J 2012 Next generation of $\mathrm{Ge}_{1-y} \mathrm{Sn}_{y}(\mathrm{y}=0.01-0.09)$ alloys grown on $\mathrm{Si}(100)$ via $\mathrm{Ge}_{3} \mathrm{H}_{3}$ and $\mathrm{SnD}_{4}$ : reaction kinetics and tunable emission Appl. Phys. Lett. 101072105 